\title{
GEOGRAFIA DE PORTUGAL; OBRAS RECENTES DE CONJUNTO
}

CARlos Alberto Medeiros ${ }^{1}$

Têm aparecido em grande número nos últimos anos obras de conjunto relativas ao nosso país, enquadradas em domínios do conhecimento diversos, que nos levam a uma reflexão renovada sobre as suas características, e por vezes até à revisão de opiniões e de maneiras de encarar a realidade portuguesa. O leque mais variado de trabalhos deste género insere-se, porventura, no âmbito da História; recordem-se, designadamente, as extensas obras colectivas dirigidas por José Mattoso, por João Medina e por Joel Serrão e A. H. de Oliveira Marques (a destes dois autores ainda em publicação), nas quais o geógrafo encontra referências desenvolvidas a muitas matérias que lhe interessam.

Uma outra obra, de Sociologia, fundamental para o conhecimento da Geografia humana portuguesa, é a que foi organizada por António Barreto, com a colaboração de mais sete investigadores, entre os quais se conta precisamente um geógrafo (João Ferrão) ${ }^{2}$. O livro reúne uma soma considerável de dados, com muitos gráficos e alguns mapas, que acompanham e ilustram textos sólidos, desenvolvidos e bem elaborados, subordinados aos seguintes títulos: Três décadas de mudança social; Indicadores da evolução social; Três décadas de consolidação do Portugal demográfico moderno; $O$ envelhecimento e as dinâmicas da população portuguesa a partir de 1960: dos dados ao dilema; A evolução dos costumes em Portugal, 1960-1995; A economia portuguesa desde 1960; As políticas sociais em Portugal; Os acordos de concertação social. Como se vê por este enunciado, o campo propriamente da Sociologia é saudavelmente ultrapassado para o de áreas científicas próximas. E, se alguns juízos de valor, comentários ou apreciações poderão gerar alguma controvérsia - que terá de se considerar desejável e estimulante, - a verdade é que o conjunto da obra constitui um contributo notável para o conhecimento da realidade portuguesa dos nossos dias; torna-se difícil especificar aquilo que mais importa à Geografia: é certo que as detalhadas análises demográficas se afiguram, à primeira vista, particularmente atraentes - mas uma leitura cuidada não deixará de revelar a importância do estudo sobre a economia, daquele que é consagrado aos "costumes" e, afinal, dos que versam as outras matérias tratadas. Estamos em presença dum livro de consulta obrigatória e frequente, em que os dados reunidos são comentados de forma cuidada e é o próprio organizador dos textos o primeiro a chamar a atenção para limitações e insuficiências de que alguns dos elementos estatísticos se revestem (veja-se a Apresentação, pp. 21-33).

Ainda na vizinhança dos confins da Geografia, mas com índole muito diferente, assinale-se uma obra sobre a economia de Portugal, incluída na colecção "Que sais-je?" e da autoria do geógrafo Michel Drain ${ }^{3}$. Não é uma análise pormenorizada do tema que se encontra neste livro, mas uma apresentação muito sintética, de acordo com a índole da colecção referida. Após um capítulo sobre a renovação de Portugal, resultante da sua evolução recente e, designadamente, da adesão à Comunidade Europeia, o autor refere-se ao espaço económico do país (desequilíbrio territorial, rede administrativa, população),para passar depois em revista as actividades agrícolas, a pesca, as actividades industriais e o turismo, terminando com um capítulo de balanço e perspectivas. Esta

\footnotetext{
${ }^{1}$ Professor Catedrático da Faculdade de Letras de Lisboa, Cidade Universitária, 1699 Lisboa Codex. Tel.: (351-1) 7940218; Fax: (351-1) 7938690.

2 A situação social em Portugal, 1960-1995, organização de António Barreto, Instituto de Ciências Sociais, Universidade de Lisboa, 1996 (510 p.).

3 L'économie du Portugal, P.U.F., Paris, 1994, (128 p.); tradução portuguesa, A economia de Portugal, DIFEL, Viseu 1995 (186 p.).
} 
síntese bem estruturada, onde estão sempre presentes uma base histórica adequada e a ponderação segura das características geográficas, é da maior utilidade para quem estuda estas matérias. Por outro lado, trata-se dum texto em que a realidade portuguesa é encarada a partir do exterior - ainda que o seu autor a conheça profundamente -, o que introduz elementos adicionais de interesse.

Esta mesma circunstância verifica-se nos dois primeiros trabalhos de índole propriamente geográfica que apareceram nos anos 90 e se referem ao conjunto do país. É também de Michel Drain a apresentação sumária de Portugal incluída no segundo volume da Géographie Universelle dirigida por Roger Brunet ${ }^{4}$ Trata-se aqui duma imagem expressiva da geografia portuguesa, onde importa sobretudo vislumbrar os traços que o autor considera relevantes, o modo como encadeia o seu estudo, e não a soma de dados reunidos. Como ponto de partida, insiste-se no facto de larga percentagem dos portugueses viver no estrangeiro. A diáspora é confrontada com as características e os condicionamentos do território português, as circunstâncias da sua diferenciação e continuidade ao longo do tempo, os seus contrastes e as assimetrias que se forjaram na organização do espaço. A partir destas e, designadamente, da oposição entre o litoral e o interior, passa-se à análise da diversidade geográfica do país, que constitui a base fundamental do trabalho e termina com uma referência aos arquipélagos da Madeira e dos Açores.

Outra obra dum geógrafo francês sobre Portugal é a de François Guichard, aparecida também em $1990^{5}$ e que surge na sequência de investigações e de trabalhos diversos que o autor dedicou ao nosso país. O livro desenvolve-se ao longo de 9 capítulos, que se agrupam em 3 partes. A primeira parte, A natureza e os homens, é uma apresentação geral do país, no que se refere aos aspectos físicos, aos fundamentos históricos e aos elementos demográficos. A segunda parte, sobre as regiões do país, assume uma perspectiva dinâmica e nela se encaram os problemas derivados das desigualdades económico-sociais do território; no primeiro capítulo faz-se alusão aos organismos que actuam a nível das regiões e aos projectos de regionalização, tema que, seis anos volvidos sobre a publicação da obra, readquiriu flagrante actualidade. Na terceira parte, A economia portuguesa, passam-se em revista, sucessivamente, o sector primário, a actividade industrial e as relações internas e com o exterior (meios de comunicação, comércio e serviços, comércio externo e turismo).

A obra, escrita em estilo vivo e atraente, sublinhado pela expressividade de muitos dos títulos das divisões a partir das quais se estrutura, reúne uma quantidade muito apreciável de informações e uma valiosa documentação cartográfica (52 mapas criteriosamente elaborados, ainda que uma ou outra vez demasiado sobrecarregados com símbolos). Os conhecimentos do autor sobre a geografia portuguesa são sólidos, e é apenas um deslize de pormenor a designação pouco feliz de Nordeste montanhoso (pp. 125-134), conferida a uma região que se estende da fronteira setentrional até às imediações da Lousã e de Castelo Branco, na parte interior do país. A selecção dos temas tratados com maior desenvolvimento, a forma equilibrada como são apresentados, as indicações bibliográficas de índole geral e específica, fazem deste livro um precioso instrumento de consulta, não só para o leitor francês, como também - porventura, mais ainda - para o português.

Tem estrutura e objectivos diferentes o excelente trabalho de Jorge Gaspar sobre as regiões portuguesas ${ }^{6}$. Na realidade, é a apresentação sistemática destas que o autor tem em vista, após um capítulo introdutório sobre Unidade e diversidade da terra portuguesa e sobre o percurso Da individualidade de Portugal à territorialidade dos portugueses. As regiões e sub-regiões consideradas ajustam-se às NUTE II e às NUTE III (ou agrupamentos destas), para além das regiões autónomas insulares (p. 17). Constituem um enquadramento muito apropriado para o tema do trabalho, no qual se analisam sucessivamente o Norte (Entre Douro e Minho, Trás-os-Montes, Douro, Entre Douro e Vouga, Área Metropolitana do Porto), o Centro (Beira Litoral, Beira Interior, Território de Viseu, Pinhal Interior e Cordilheira Central), Lisboa e Vale do Tejo (Oeste, Ribatejo, Área Metropolitana de Lisboa), o Alentejo (Alto,Central, Baixo, Litoral), o Algarve (Oriental, Central, Ocidental), a

\footnotetext{
${ }^{4}$ Em rigor, apesar da seriação que vem indicada em todos eles, não estão numerados os volumes. Veja-se Denise Pumain, Thérèse Saint-Julien, Robert Ferras (e colaboradores), France, Europe du Sud, Hachette/Reclus, Paris, 1990. A parte sobre Portugal ocupa quatro dezenas de páginas (pp. 264-303).

5 Géographie du Portugal, Masson, Coll. Géographie, Paris, 1990 (224 p.).

${ }^{6}$ As regiões portuguesas, Direcção-Geral do Desenvolvimento Regional, Lisboa, 1993 (240 p.).
} 
Madeira (Porto Santo, Norte e Sul da ilha da Madeira, Área Metropolitana do Funchal) e os Açores (Grupos Oriental, Central e Ocidental).

Este livro impõe-se pelo equilíbrio com que foi estruturado, pela rara elegância literária do conjunto do texto, pela riqueza da informação, em que se conjugam os dados estáveis, a partir dos quais se individualizaram as várias unidades, a apresentação breve de aspectos físicos cuja ponderação se revele necessária, os fundamentos históricos da realidade presente e os desenvolvimentos recentes desta, na rápida sucessão de acontecimentos que os caracteriza. Um magnífica selecção de fotografias, em regra excelentemente reproduzidas, e de extractos do mapa do país a 1:50.000, para além de outras ilustrações, enriquece consideravelmente o texto e torna ainda mais proveitosa a sua utilização. Um ou outro leitor estimariam talvez vê-lo apoiado em maior soma de dados estatísticos - para o que contribuirá a circunstância de ter sido o seu autor, o geógrafo português que mais contribuiu, no seu país, para a difusão dos métodos quantitativos no estudo da geografia humana. Contudo, justifica-se a opção deliberada assumida neste caso, pois a profusão de elementos e indicadores numéricos, referidos a um ano ou a um período circunscrito, mas sempre necessariamente fugazes, prejudicaria a imagem que se pretende dar das regiões e que não é redutível a uma combinação de estatísticas, mas onde elas são apenas chamadas a avivar esta ou aquela característica.

Em suma, a presente obra de Jorge Gaspar constitui verdadeiramente um marco de referência obrigatória para o conhecimento das regiões portuguesas nestes finais do século XX.

Depois de ter organizado e actualizado a monumental Geografia de Portugal, em quatro volumes (1987-1991), em que a sua colaboração se junta aos textos mais antigos de Hermann Lautensach e Orlando Ribeiro, Suzanne Daveau oferece-nos agora uma obra autónoma e sintética sobre o conjunto do país ${ }^{7}$ De concepção original, ela divide-se em cinco partes. Na primeira analisam-se os reflexos da posição de Portugal no Mundo, em que avultam as características climáticas, mas outros aspectos físicos e humanos são também apresentados. A segunda parte é dedicada ao enquadramento de Portugal, em termos de maior proximidade geográfica (um pequeno segmento da Península Ibérica, junto ao Atlântico subtropical), e nela é concedida particular atenção ao relevo, à hidrologia, à população e a aspectos histórico-sociais. Na terceira parte, sobre Diversidade e organização do território, apresentam-se os seus conjuntos regionais e a forma como estão relacionados. A quarta parte corresponde ao estudo da vida rural e do modo como influenciou decisivamente a paisagem. Finalmente, na quinta parte, Áreas e eixos urbanizados, estudam-se os espaços mais dinâmicos do país, com saliência para o fenómeno urbano, e também para os transportes e as indústrias. Cada uma destas partes está organizada em temas,tratados em duplas páginas, o que permite maior flexibilidade e autonomia na consulta, facilitando ao leitor a procura do que mais lhe interesse, ainda que os vários assuntos estejam dispostos ordenadamente..

Diversos aspectos chamam a atenção neste livro: a preocupação de enquadrar o país em contextos geográficos mais ou menos amplos, conforme atrás ficou referido; a numerosa e diversificada ilustração, que não é simples complemento do texto, mas importante elemento de referência e comentário; o tratamento de diversos temas através de exemplos concretos, a que é conferido o desenvolvimento adequado, e que permitem encará-los de forma mais precisa; a solidez e riqueza da informação, num texto muito claro e atraente, em que se recusam as interpretações simplificadoras (e que, por via disto, se podem tornar deformadoras), não se escamoteando a complexidade de muitos dos fenómenos estudados. A inclusão de referências bibliográficas, ainda que sumárias, e à qual renunciou a autora, enriqueceria ainda mais a obra, e não me parece que, de modo algum, a viesse tornar de menos "fácil manejo" (p. 6).

De qualquer forma, só por excessiva modéstia Suzanne Daveau terá sido levada a insistir no seu propósito de fornecer "uma exposição simples", que "não é uma obra de tipo universitário" (p. 6). Torna-se desejável, sem dúvida, que o livro tenha ampla difusão num público numeroso e diversificado - e reúne todas as condições para isso; mas estou também convencido de que será largamente utilizado e divulgado na Universidade, por estudantes e docentes, que nele encontrarão

\footnotetext{
${ }^{7}$ Portugal geográfico, Edições João Sá da Costa, Lisboa, 1995 (223 p.)
} 
informações diversas, sugestões de método e pontos de partida para reflexões proveitosas sobre o significado e o encadeamento dos mais variados fenómenos que se entrecruzam no estudo da geografia de Portugal.

Além dos livros referidos, que se devem a um único autor ${ }^{8}$, haverá que referir dois trabalhos colectivos, coordenados e, na sua larga maioria, elaborados por geógrafos.

Portugal. Perfil geográfico tem direcção de Raquel Soeiro de Brito, que contou essencialmente com a colaboração de docentes e investigadores que com ela trabalham na Universidade Nova de Lisboa ${ }^{9}$. Trata-se duma obra onde, em oito divisões principais, estão ordenadas matérias diversas que têm como ponto de partida as origens do país e recobrem os aspectos físicos e humanos do território, bem como problemas económicos e ligados aos desequilíbrios regionais e à integração na União Europeia, com um capítulo à parte dedicado aos arquipélagos da Madeira e dos Açores. Aqui se apresentam os títulos daquelas divisões, as quais são precedidas por uma breve introdução sobre O espaço geográfico português: Os primórdios de Portugal; Quadro natural; As gentes e a sua distribuição; A vida dos homens (habitação, actividades do espaço rural, pesca, energia, industrialização); A vida de relação (transportes, telecomunicações, actividades terciárias, turismo); Política económica e desequilíbrios regionais; As ilhas; Portugal e a Europa Comunitária.

Como se vê, há a preocupação de fornecer um panorama tão completo quanto possível da geografia de Portugal. Neste sentido, os autores colheram um conjunto valioso de dados, comentaram-nos e acrescentaram nos seus textos informações e reflexões diversas sobre os assuntos tratados, que tornam, em geral, muito proveitosa a consulta deste livro. É claro que, como resulta habitual nestes casos, poderá dizer-se que o nível das várias colaborações ficou um tanto desigual. Nem sempre se explicitam claramente condicionamentos ou lacunas de determinados dados mais recentes (como no caso da emigração); por outro lado, alguns leitores gostariam certamente de ver concretizados os fundamentos ou as fontes de determinadas figuras. Mas o que mais importa sublinhar são os méritos desta obra, o cuidado com que se abrangem e articulam os mais diversos temas, a abertura para domínios do conhecimento próximos da Geografia. Conforme se disse atrás, estamos em presença dum livro que se revelará da maior utilidade para quem dele se servir.

Outra obra colectiva, com índole e apresentação diferentes, é o volume relativo à Geografia que está incluído na Enciclopédia Temática Portugal Moderno e foi coordenado por Jorge Gaspar ${ }^{10}$. Como este acentua devidamente, o trabalho em causa, subordinado aos moldes da enciclopédia de que faz parte, "não foi concebido como uma tradicional Geografia de Portugal, até porque alguns dos temas que aí teriam pertinência já foram apresentados noutros volumes". Mesmo assim, "procurou-se uma grande diversidade temática" e reunir autores (das "escolas" geográficas de Coimbra e de Lisboa) que introduzissem, "na medida do possível, a variedade de métodos e de posicionamentos teóricos que se podem encontrar actualmente entre os geógrafos portugueses" (p. 7). Também aqui se poderão detectar disparidades nas várias colaborações e, além disto, demoras na impressão do volume fizeram que fosse distribuído tardiamente, sem a possibilidade de utilização de alguns dados mais recentes. Seja como for, temos aqui um livro solidamente fundamentado e com muita ilustração, destinado a constituir valioso instrumento de trabalho e divulgação. Tal como se fez em relação aos outros aqui referidos, vale a pena citar os títulos das matérias tratadas. Após a Introdução, temos: Relevo de Portugal; O clima de Portugal; A vegetação e os solos; Génese das paisagens tradicionais; $O$ mundo rural: da montanha à pluriactividade; Urbanização e cidades; Serviços em Portugal; Actividade industrial; Turismo no Portugal contemporâneo; Equipamentos colectivos: necessidade, acesso e bem estar; Poder local.

Assim, após o relevante acontecimento que foi a publicação da Geografia de Portugal, em quatro volumes, de Orlando Ribeiro, Hermann Lautensach e Suzanne Daveau, na passagem dos anos 80 para os 90, ao longo destes últimos sucederam-se diversos trabalhos de conjunto sobre a geografia de Portugal. A breve notícia que deles aqui se apresenta dá conta do seu carácter sintético, mas também da grande soma de dados e da diversificada informação temática que proporcionam,

\footnotetext{
8 Mencione-se, a propósito, que apareceu em 1996 a $4^{\text {a }}$ edição, bastante ampliada e parcialmente actualizada em relação à $2^{\mathrm{a}}$ (1991), dum trabalho da mesma índole da autoria de quem escreve estas linhas: Geografia de Portugal. Ambiente natural e ocupação humana; uma intodução, Editorial Estampa, $4^{\mathrm{a}}$ edição, Lisboa, 1996 (282 p.).

9 Portugal. Perfil geográfico, direcção de Raquel Soeiro de Brito, Editorial Estampa, Lisboa, 1994 (415 p.).

10 Enciclopédia Temática Portugal Moderno-Geografia, coordenação e introdução de Jorge Gaspar, Pomo, Lisboa, 1991 (222 p.).
} 
bem como das pistas que abrem para uma reflexão aprofundada sobre vários assuntos e as questões metodológicas que o seu estudo suscita. Entretanto, continua a faltar uma obra desenvolvida, com contributos dos geógrafos que mais se especializaram na investigação relacionada com os vários temas, à maneira dos extensos trabalhos de História de Portugal referidos no início. 
